\title{
DA ÓRBITA NO LITÍGIO: UMA ANÁLISE DO DIREITO SISTÊMICO E SUA EFICÁCIA NOS SISTEMAS DE CONSTELAÇÕES FAMILIARES
}

\section{OF ORBIT IN LITIGATION: AN ANALYSIS OF SYSTEMIC LAW AND ITS EFFECTIVENESS IN FAMILY CONSTELLATION SYSTEMS}

\author{
Norton Maldonado Dias ${ }^{1}$ \\ Marcelo Azevedo Rieffel ${ }^{2}$
}

\section{RESUMO}

O atual cenário de injustiças sociais acaba por exigir do nosso Sistema Judiciário novos caminhos para resolução de conflitos, uma vez que, a pura aplicação da lei no Sistema Legalista não vem conseguindo produzir a paz social que se espera da justiça. Tal necessidade conduz os estudos sobre o denominado Direito Sistêmico, uma forma de utilização do Ordenamento Jurídico dita como mais humanizada, uma vez que busca a resolução consensual de litígios através de métodos oriundos de outras ciências sociais. Dentre as técnicas utilizadas, o presente trabalho busca analisar através de pesquisa bibliográfica, a conhecida técnica de Constelação Familiar desenvolvido pelo psicoterapeuta alemão Bert Hellinger, que vem se mostrando eficiente na resolução consensual de litígios quando aplicado nas Varas de Família do País. Através do aprofundamento acerca do assunto Direito Sistêmico e das formas de resolução consensual de litígios admitida em nosso Ordenamento Jurídico, o presente trabalho busca comprovar se de fato o Direito Sistêmico é em sua prática mais humanizado e se as Constelações Familiares são capazes de produzir bons resultados quando aplicadas aos processos pertencentes ao Direito de Família.

\footnotetext{
${ }^{1}$ Mestrado em Direito -Centro Universitário Eurípides de Soares da Rocha, com especializações em Direito na Pós-graduação da UEL - Universidade Estadual de Londrina - Paraná e na PUCMG. Graduação em Direito - Centro Universitário Eurípides de Soares da Rocha. Professor na Graduação e na Pós-Graduação da Faculdade de Direito de Sinop . Professor convidado na pós-graduação do Instituto EducareMT. Professor dos cursos preparatórios da OAB no Programa "Resolve Direito"(Unifasipe) e no Ishikawa Centro de Estudos e Práticas Jurídicas. Advogado ocupante da cadeira 31 da (ASCL) Academia Sinopense de Ciências e Letras. Atua como advogado e com experiência no Poder Legislativo Municipal. Membro do CONPEDI (Congresso Nacional de Pós-Graduação em Direito).E-mail: maldonadodias@hotmail.com.br. ORCID. https://orcid.org/0000-0001-5506-5651

2 Especialista em Direito na pós-graduação da UNIASSELVI, advogado atuante em Cáceres - MT. Formado em Direito na Faculdade de Sinop (FASIPE) com prática no NPJ - Núcleo de Prática Jurídica cuja a temática da conclusão do curso foi Sistema de Constelação Familiar como forma de Resolução de Conflitos na seara do Direito de Família. E-mail: ORCID
} 
Palavras chaves: Constelação Familiar; Direito de Família; Direito Sistêmico.

\begin{abstract}
The current scenario of social injustices ends up demanding from our Judiciary System new ways to resolve conflicts, since the pure application of the law in the Legal System has not been able to produce the social peace that is expected from justice. This need leads to studies on the so-called Systemic Law, a way of using the Legal System is said to be more humanized, since it seeks consensual resolution of disputes through methods from other social sciences. Among the techniques used, the present work seeks to analyze, through bibliographic research, the well-known Family Constellation technique developed by the German psychotherapist Bert Hellinger, who have been proving efficient in the consensual resolution of disputes when applied in the Family Courts of the Country. on the subject of Systemic Law and the forms of consensual resolution of disputes admitted in our Legal System, the present work seeks to prove whether Systemic Law is in its practice more humanized and whether Family Constellations are capable of producing good results when applied to processes pertaining to Family Law.
\end{abstract}

Key words: Family Constellation; Family Law; Systemic Law.

\title{
1 CONSIDERAÇÕES INICIAIS
}

O atual cenário de injustiças sociais acaba por exigir do nosso Sistema Judiciário novos caminhos para resolução de conflitos, uma vez que, a pura aplicação da lei no Sistema Legalista não vem conseguindo produzir a paz social que se espera da justiça.

Com fundamento no parágrafo $3^{\circ}$ do artigo $3^{\circ}$ do Código de Processo Civil através da Lei n. 13.105 de 2015 (BRASIL, 2015a) e com a Resolução no 125/2010 do CNJ (Conselho Nacional de Justiça), o Direito Sistêmico tem solucionado conflitos, no âmbito do Direito de Família, através da técnica terapêutica denominada Constelações Familiares.

A expressão 'Direito Sistêmico' é uma forma diferenciada de se analisar os conflitos judiciais que busca profunda reflexão, muitas vezes, terapêutica do atual litígio afim de se encontrar o motivo do conflito, sugerindo passos que busquem a harmonização tanto no âmbito familiar, bem como social.

Trata-se de um conjunto de ações, intervenções, exercícios e práticas que buscam ampliar a visão dos litigantes para além do processo judicial, ou seja, trata-se 
de um conjunto de técnicas que vem se mostrando de grande eficácia na resolução de conflitos ligados ao Direito de Família, reduzindo de forma efetiva a tensão do litígio em foco, sendo possível o reconhecimento do problema, ampliando o campo de visão do terapeuta sobre o conflito e mostrando os possíveis caminhos para resolução através da pacificação.

O presente trabalho busca, através de pesquisa dedutiva bibliográfica, em sua forma analítica, ponderar questões acerca de um novo Direito, tentando compreender as razões e como tais práticas ocorrem para o efeito do expressivo índice de resolutividade verificável na aplicação das Constelações Familiares.

Dessa forma, vale destacar a justificativa correspondente aos altos índices de resolutividade que, inevitavelmente, atraem a atenção como uma técnica com potencial de, realmente, ajudar em uma crise que já se alastra, em alguns casos, há muito tempo.

Valendo, por isso, a compreensão da sua aplicabilidade relacionada aos Sistemas de Constelações Familiares associada à sua eficiência, tornando-se relevante ao analisarmos o Direito de Família cujo objetivo principal é a manutenção do núcleo familiar, buscando sempre a resolução de litígios da forma consensual e menos prejudicial ao ambiente familiar.

\section{A CONCILIAÇÃO COMO MEIO EFICAZ DE RESOLUÇÃO CONSENSUAL DE LITÍGIOS E A BUSCA PELA PACIFICAÇÃO SOCIAL}

As soluções alternativas de litígios são institutos que sempre acompanharam o desenvolvimento social, já que, desde as primeiras aglomerações humanas, é possível perceber a necessidade que todos temos de nos relacionar um com os outros, buscando o diálogo e a negociação ainda que primitiva como resolução de conflitos. Institutos esses que, quando absorvidos e desenvolvidos pelo ordenamento Jurídico do Estado, demonstram ser eficazes formas de pacificação social, trazendo ainda, um alívio ao exercício da função jurisdicional e ocasionando uma diminuição no número de pendências judiciais.

A busca por formas de conciliação é de suma importância, já que a Justiça Brasileira vem passando por uma enorme carga de litígios, reflexo da própria evolução 
social. Através das resoluções consensuais, o Ordenamento Jurídico busca afastar-se do constante formalismo exigido pelas formas processuais com o principal objetivo de tornar o acesso à justiça mais célere e eficaz. Segundo o pesquisador Guilherme Silva Barbosa Fregapani (2016, p. 100):

Conforme a esse princípio, que norteou toda a recente reforma do Código de Processo Civil brasileiro, foi resgatada pelos nossos renomados processualistas a significativa importância dos meios alternativos de soluções de conflitos como verdadeiros e eficazes mecanismos de se fazer a justiça e de se alcançar a tão buscada paz social.

Desde sua origem, o Ordenamento Jurídico buscou o meio menos prejudicial para resolução de conflitos entre as partes, a atual crise no Sistema Jurídico Brasileiro acabou desmoralizando todo o sistema que atualmente não possui grande credibilidade aos brasileiros, a morosidade e o formalismo exigido afastam a busca pela paz social caracterizada pelo sentido de Justiça, o incentivo aos meios alternativos de soluções de conflitos pode ser a solução mais eficaz para mudar esse atual cenário.

Basicamente, são conhecidas três formas diversas de obter-se a solução de um conflito: a autotutela, a heterocomposição e a autocomposição. A primeira, também conhecida como autodefesa é a solução de imposição de uma das partes sobre a outra em um conflito, isto é, cada um dos litigantes busca impor sua vontade e pretensão pela força. De acordo com o doutrinador Carlos Henrique Bezerra Leite (2007, p. 108) é possível notar que: "Aqui não há a figura de um terceiro para solucionar o litígio, e sim a imposição da decisão por uma das partes, geralmente a mais forte, do ponto de vista físico, econômico, político ou social".

Diante disso, a autotutela é o meio mais antigo e imperfeito de se buscar a paz social, já que favorece sempre o mais forte, não levando em consideração quem tem razão ou não. É importante saber que a autotutela ainda é aceita pelo atual Ordenamento Jurídico em casos excepcionais, entre os casos podemos citar o direito à legítima defesa e no desforço de força necessária para a manutenção da posse.

Com a evolução social e a formação de sociedades mais complexas, houve a necessidade de se estabelecer normas jurídicas a serem aplicadas por um terceiro na 
resolução de um litígio, sendo este a representatividade do Estado, e responsável a sentenciar a respeito de determinada lide. A conhecida heterocomposição é a utilização de um terceiro que analisará os fatos expostos a ele, e determinará uma decisão, conhecida como sentença, acerca do assunto.

A heterocomposição é a base do Ordenamento Jurídico Brasileiro, uma vez que cabe aos juízes analisar os litígios presentes. Outra forma conhecida de heterocomposição é a arbitragem, tal instituto relaciona-se com a escolha realizada pelas partes, elegendo um terceiro que analisará o caso e dará uma decisão com força de sentença, os instrumentos arbitrais são classificados como: a) Cláusula arbitral: é a arbitragem que fica estabelecida por contrato, em que as partes elegem em convenção que a arbitragem será a primeira forma utilizada caso haja um conflito. Conforme expresso no caput do artigo 4ํㅜ da Lei n 9307/ 96, "A cláusula compromissória é a convenção através da qual as partes em um contrato comprometem-se a submeter à arbitragem os litígios que possam vir a surgir, relativamente a tal contrato" (BRASIL, 1996, p. 1).

Também, vale explicitar a cláusula b) Compromisso arbitral: fica estabelecido a arbitragem por instrumento específico, assinado por ambas as partes. Nesta situação, o conflito já existe, as partes apenas convencionam se este deverá ser solucionado pela arbitragem. Tendo previsão legal, no caput do artigo 9ำ da supracitada Lei, (BRASIL, 1996, p.1) "O compromisso arbitral é a convenção através da qual as partes submetem um litígio à arbitragem de uma ou mais pessoas, podendo ser judicial ou extrajudicial"

Em relação ao prazo para que a sentença seja proferida, o artigo 23 da referida lei (BRASIL, 1996, p.1) traz expresso que "A sentença arbitral será proferida no prazo estipulado pelas partes. Nada tendo sido convencionado, o prazo para a apresentação da sentença é de seis meses, contado da instituição da arbitragem ou da substituição do árbitro".

Via de regra, não são cabíveis recursos em relação às decisões proferidas por arbitragem, como exceção é possível que hajam embargos de declaração quando houver obscuridade, contradição ou omissão. Caso a arbitragem contenha algum vício ou ilegalidade, será cabível ação anulatória ao Poder Judiciário no prazo de 90 dias, caso seja confirmada tal nulidade, o processo de arbitragem será novamente realizado. 
A autocomposição, por sua vez, busca a solução pacífica do litígio, por obra das partes envolvidas, sendo de sua iniciativa e por elas próprias realizadas, muitas vezes com a contribuição de um terceiro, através da mediação ou da conciliação. $\mathrm{Na}$ mediação, o terceiro mediador é necessário quando as partes não conseguem chegar a uma solução, cabendo-lhe estimular e ajudar os próprios interessados para que ajam afim de chegar a um acordo. Em suma, o mediador age de forma a acelerar a composição, organizando-a e apresentando elementos às partes que, muitas vezes, no calor da discussão, são imperceptíveis. Segundo Fregapani (2016, p. 101).

$\mathrm{Na}$ técnica de mediação, um terceiro não interessado (o mediador) auxilia as partes a definirem suas posições em relação aos pontos em litígio e a explorarem as possibilidades de solução negociada. $O$ mediador não avalia ou sequer emite opinião sobre o caso, mas apenas facilita o intercâmbio de informações, idéias e alternativas para solução do litígio.

Ainda acerca do assunto, a própria Lei ㄲo 13.140 de 2015, que dispõe sobre a mediação entre particulares como meio de solução de controvérsias e sobre a autocomposição de conflitos, em seu artigo 1ํㅡㄹ parágrafo único, considera a mediação como: " [...] a atividade técnica exercida por terceiro imparcial sem poder decisório, que, escolhido ou aceito pelas partes, as auxilia e estimula a identificar ou desenvolver soluções consensuais para a controvérsia" (BRASIL, 2015b, p. 1).

A mediação tem como objetivo a priorização dos laços intrínsecos a um relacionamento, sendo a vontade das partes envolvidas no litígio postas em primeiro plano, ressaltando-se os pontos positivos de cada um dos litigantes, para que com o auxílio do agente mediador, as partes estabeleçam um diálogo e, a partir de uma análise de tudo que já foi apresentado, possam encontrar uma solução consensual para as controvérsias em questão. Para Maria de Nazareth Serpa, (1997, p. 05) mediação trata-se de um:

Processo informal, voluntário, onde um terceiro interventor, neutro, assiste aos disputantes na resolução de suas questões. O papel do interventor é ajudar na comunicação através de neutralização de emoções, formação de opções e negociação de acordos. Como o agente fora do contexto conflituoso, funciona como um catalizador de 
disputas, ao conduzir as partes às suas soluções, sem propriamente interferir na substância destas.

O agente mediador, no atual Código Processual Civil - CPC, (BRASIL, 2015a) é tratado como auxiliar da justiça, assim como os escrivães, peritos e tradutores. A mediação traz, à luz da discussão dos mediados, as principais questões que originam conflitos, propiciando uma maior comunicação entre as partes, e, apreciando os fatos através do diálogo, os mesmos constroem por si só o consenso necessário para resolução de suas pendências.

A partir do conhecimento técnico, o mediador contribui para o esclarecimento das problemáticas presentes em um litígio. Eliana Riberti Nazareth (2006, p. 130) define mediação como "Um método de condução de conflitos, aplicado por um terceiro neutro e especialmente treinado, cujo objetivo é restabelecer a comunicação produtiva e colaborativa entre as pessoas que se encontram em um impasse, ajudando-as a chegarem a um acordo".

É importante enfatizar que o CPC, (BRASIL, 2015a), ao incentivar os institutos da mediação e da conciliação, reconheceu que a base da sociedade é a família, fornecendo a ela especial proteção. Diante disso, além de submeter as demandas familiares com maior presteza, acabou por apontar que a resolução consensual nesses litígios deve ser sempre motivada, conforme dispõe o artigo 694 do referido Código: "Nas ações de família, todos os esforços serão empreendidos para a solução consensual da controvérsia, devendo o juiz dispor do auxílio de profissionais de outras áreas de conhecimento para mediação e conciliação" (BRASIL, 2015a).

Por sua vez, a conciliação busca a pacificação entre as partes diante um litígio, onde os litigantes atuam em conjunto com um terceiro, o conciliador, que incentiva e conduz o diálogo, sem opor-se. Nessa situação, o agente conciliador faz apontamentos e sugestões a fim de buscar a resolução consensual. De acordo com Roberto Portugal Barcellar (2003, p. 66), a conciliação pode ser entendida como:

Um processo técnico (não intuitivo), desenvolvido pelo método consensual, na forma autocompositiva, em que terceiro imparcial, após ouvir as partes, orienta-as, auxilia, com perguntas, propostas e sugestões a encontrar soluções (a partir da lide) que possam atender 
aos seus interesses e as materializa em um acordo que conduz à extinção do processo judicial.

A conciliação não se limita apenas a solucionar o litígio, tem como objetivo também restabelecer a própria relação entre as partes, tornando-a o mais harmoniosa possível.

Em um aspecto geral, pode-se definir a conciliação como sendo uma técnica que compreende um conjunto de atos pelos quais o agente conciliador atua facilitando a negociação, realizando apontamentos e sugerindo um maior estímulo ao diálogo entre as partes, propiciando um ambiente ideal para que seja encontrada a melhor solução para a situação apresentada.

Tanto a mediação quanto a conciliação devem ser estimuladas não apenas na audiência de conciliação e mediação, propriamente dita, no artigo 33 do CPC (BRASIL, 2015a), mas a qualquer momento do processo, incluindo a audiência de instrução e julgamento realizada pelo Juiz competente, conforme dispões o artigo 339 do referido código: "Instalada a audiência, o juiz tentará conciliar as partes, independentemente do emprego anterior de outros métodos de solução consensual de conflitos, como a mediação e a arbitragem" (BRASIL, 2015).

Os Tribunais têm como função manter um cadastro atualizado de agentes mediadores e conciliadores, constando a área de atuação de cada profissional cadastrado no sistema, sendo ainda requisito, a capacitação mínima através de curso, com certificado expedido conforme trata o artigo 167 do CPC (BRASIL, 2015a).

No entanto, para incentivar ainda mais a autocomposição, é importante salientar que os próprios interessados podem em comum acordo escolher um mediador ou conciliador que, não necessariamente precisa possuir cadastro nos órgãos competentes, conforme expresso no caput do artigo 168 do CPC (BRASIL, 2015a):

As partes podem escolher, de comum acordo, o conciliador, o mediador ou a câmara privada de conciliação e de mediação. § 1ㅇ $\mathrm{O}$ conciliador ou mediador escolhido pelas partes poderá ou não estar cadastrado no tribunal. $\S 2^{\circ}$ Inexistindo acordo quanto à escolha do mediador ou conciliador, haverá distribuição entre aqueles cadastrados no registro do tribunal, observada a respectiva formação. 
As técnicas de autocomposição são aplicadas tanto na mediação quanto na conciliação, não há limites ou restrições de tempo para a realização da sessão, podendo haver ainda mais de uma audiência de conciliação ou mediação se assim for necessário. É evidente que, a busca do atual Sistema Jurídico Brasileiro pela resolução consensual de litígios, a autocomposição, é vista como valioso instrumento de pacificação da sociedade, tanto na mediação quanto na conciliação. Essa busca não é pela definição de quem ganhou e quem perdeu a causa e sim, permitir, que os próprios litigantes construam e busquem a solução do conflito de tal forma que agrade ambas as partes.

\section{O DIREITO SISTÊMICO E A BUSCA PELA HUMANIZAÇÃO DO ATUAL ORDENAMENTO JURÍDICO}

O Conselho Nacional de Justiça - CNJ - é uma instituição pública cujo objetivo principal é aperfeiçoar o trabalho do sistema judiciário brasileiro, dentre outras preocupações. Essa instituição visa tornar o meio jurídico nacional mais transparente e efetivo, e, através de suas diretrizes, estabelece uma maior humanização do Direito Brasileiro incentivando a resolução de litígios sem que haja a necessidade de uma sentença promulgada por um Juiz.

Neste sentido, por meio da Resolução no 125 de 2010, o CNJ institui uma política de incentivo à solução de litígios em sua forma consensual, deixando claro que cabe a todos os operadores do Direito e, inclusive, à Instituição prezar pela forma menos agressiva para as partes, isto é, assegurar a todos o direito de resolver os litígios pelos meios mais apropriados à sua natureza e peculiaridade.

Dando especial atenção ao parágrafo único do Artigo 1ำ da referida Resolução, que traz expresso a responsabilidade intrínseca dos órgãos judiciários ante o incentivo a realização da audiência de conciliação e mediação anterior à audiência de julgamento:

Aos órgãos judiciários incumbem, nos termos do art. 334 do Novo Código de Processo Civil combinado com o art. 27 da Lei de Mediação, antes da solução adjudicada mediante sentença, oferecer outros 
mecanismos de soluções de controvérsias, em especial os chamados meios consensuais, como a mediação e a conciliação, bem assim prestar atendimento e orientação ao cidadão. (BRASIL, 2010).

O Conselho Nacional de Justiça deixa claro que incumbe aos órgãos judiciários a busca pela resolução consensual de litígios, seja através da conciliação, mediação ou qualquer outro meio aceito que traga uma maior satisfação e torne o processo menos moroso, já que a busca pela resolução da lide, sem que haja a necessidade de uma sentença propriamente dita, traz maior celeridade ao processo e, por sua vez, uma maior satisfação.

Além disso, a mesma Resolução enuncia, em seu artigo 4ํㅜㄹ a responsabilidade do CNJ quanto a organização de programas que incentivem a autocomposição, a mediação e a conciliação, prezando pela pacificação social. $O$ artigo traz expresso que "Compete ao Conselho Nacional de Justiça organizar programa com o objetivo de promover ações de incentivo à autocomposição de litígios e à pacificação social por meio da conciliação e da mediação". (BRASIL, 2010).

Desta forma, o Conselho irá auxiliar os tribunais na organização dos serviços supracitados, podendo ainda firmar parcerias com órgãos públicos e privados que ofereçam cursos de capacitação nas áreas de mediação e conciliação, bem como auxiliar no processo de cadastramento desses agentes.

Ainda a respeito do tema, o CPC (2015a), inovou ao trazer expresso no parágrafo $3^{\circ}$ do Artigo $3^{\circ}$ que "A conciliação, a mediação e outros métodos de solução consensual de conflitos deverão ser estimulados por juízes, advogados, defensores públicos e membros do Ministério Público, inclusive no curso do processo judicial”. (BRASIL, 2015).

Restando claro a intenção de todo ordenamento jurídico brasileiro ao incentivo a resolução de litígios em sua forma consensual uma vez identificada a deficiência do sistema jurídico, causando muitas vezes, às partes interessadas no processo, danos por vezes maiores que a própria sentença estipulada pelo Juiz.

Diante este cenário, a busca por outros métodos que possam ser utilizados na solução consensual de conflitos trouxe à luz das discussões a utilização do Direito de forma mais humanizada, podendo conciliá-lo com outras ciências sociais que auxiliarão 
na solução menos prejudicial para ambas as partes. O Direito Sistêmico estabelece que, essa nova forma de justiça, é um direito humanizado que se altera conforme as relações processuais. Nesse caso, a parte (pessoa) e sua plena satisfação são importantes a todo o sistema jurídico, de forma que, o operador do direito sistêmico, tem como objetivo promover, acima de tudo, os direitos fundamentais e a justiça com dignidade, firmando o valor de cada indivíduo na relação processual.

Juiz no Estado da Bahia, Sami Storch (2015, p. 95) foi um dos primeiros operadores brasileiros a utilizar o Direito Sistêmico na resolução de litígios e afirma que

\begin{abstract}
O Direito Sistêmico é, antes de tudo, uma postura. É uma nova forma de viver e de se fazer justiça, buscando o equilíbrio entre o dar e o receber, de modo a trazer paz para os envolvidos em um conflito. O Direito Sistêmico, em termos técnico-científicos, é um método sistêmico fenomenológico de solução de conflitos, com viés terapêutico, que tem por escopo conciliar, profunda e definitivamente, as partes, em nível anímico, mediante o conhecimento e a compreensão das causas ocultas geradoras das desavenças, resultando daí paz e equilíbrio para os sistemas envolvidos.
\end{abstract}

Sendo assim, o Direito Sistêmico traduz o incentivo a uma nova forma de se operar o direito, sendo constituído também a partir da Declaração Universal dos Direitos Humanos. Tal direito compromete-se, em toda sua estrutura, com a liberdade, solidariedade e tolerância entre os indivíduos, sempre levando em consideração o pluralismo, isto é, a diversidade cultural e o respeito ao próximo alinhado aos direitos e garantias fundamentais, expressos também em nossa Carta Magna.

A partir deste incentivo e da consciência crítica no contexto das relações conflituosas, o Direito Sistêmico concretiza-se como um direito direcionado para manutenção das garantias fundamentais dos indivíduos por meio de soluções pacificadoras que enalteçam o valor de cada parte envolvida na lide. Diante disso, os gestores da justiça irão agir de forma a garantir a paz social, reconhecendo ser este o ensejo de toda pessoa humana.

Deste modo, o Direito Sistêmico caracteriza-se como um conjunto de ações, intervenções, técnicas e práticas sensoriais cujo objetivo é de se ampliar a ótica dos litigantes, direcionando-os para além do litígio. Esses, por sua vez, serão conduzidos 
por um operador capacitado a analisar de forma aprofundada a trazer à luz da discussão realidades muitas vezes invisíveis aos que se encontram no calor da discussão, orientando as partes a uma solução menos prejudicial alcançando a paz social dentro de uma relação interpartes.

As análises realizadas, através do Direito Sistêmico, invariavelmente envolvem à busca da inclusão de todos, a busca pelo equilíbrio entre as partes e a observância dos atos que precedem o litígio. A intervenção do operador do Direito Sistêmico deve ser sempre imparcial, requer alta sensibilidade, uma vez que ele irá analisar em sua profundidade as possíveis causas para o litígio em questão.

O movimento do Direito Sistêmico ganha potencial aceitação em um cenário atual de tantas injustiças, em que as partes integrantes de um processo judicial dificilmente ficam satisfeitas com as decisões judiciais proferidas, prolongando as discussões através de intermináveis recursos, que muitas vezes são utilizados como forma de tornar o processo ainda mais moroso, eternizando-os em um sistema falido, precário e burocrático. Neste cenário, permanece evidente outro sentimento, o de que o direito positivado por leis não é suficiente para defender os direitos humanos, ou ainda, resguardar os direitos das partes envolvidas em um processo.

O Direito Sistêmico nasce da necessidade do Estado e dos operadores do direito se aproximarem das partes envolvidas em um litígio, após verificar-se que as decisões proferidas judicialmente são incapazes de trazer a paz social. Sendo considerado um direito humanizado, inclusivo, que se adapta e se movimenta conforme as relações processuais, sendo a pessoa envolvida no litígio considerada como fundamento e fim de todo sistema jurídico. O operador de direito concentra em suas mãos a responsabilidade e o respeito à dignidade da pessoa, mediante a tutela e promoção de tais direitos, garantindo com isso, o valor de cada pessoa que venha integrar o processo judicial.

Tal direito traduz a tomada de consciência e a constante evolução de um novo Sistema Judiciário, que está sendo construído com base na Declaração dos Direitos Humanos. É um direito comprometido com a liberdade, a solidariedade e o respeito ao próximo, em plena conexão com os direitos conhecidos como fundamentais. 
É fundamental que haja operadores do direito que incentivem a utilização do direito em sua forma sistêmica, que se empenhem em conduzir os conflitos judiciais de tal forma que a paz social seja alcançada por ambas as partes.

A consciência coletiva no qual se vincula todo o Direito Sistêmico encontra-se fixada pela análise de preceitos que foram observados ao longo de décadas, estes são denominados como Leis Sistêmicas.

A primeira lei direcionada à harmonização do sistema expressa que todos os integrantes de determinado grupo possuem idêntico direito de pertencerem a este grupo, revelando por si uma consciência que não tolera a exclusão de seus integrantes.

O psicoterapeuta Bert Hellinger (2003, p. 65), ao referir-se à Lei Sistêmica, que diz, "Nesta lei observa-se a presença das denominadas lealdades sistêmicas, as tragédias que se vinculam a idênticos padrões de comportamento que se repetem dentro de um mesmo grupo".

Identificar os padrões de comportamento de cada integrante do grupo é tarefa essencial ao operador do Direito Sistêmico, pois, através disso, é possível estabelecer padrões de comportamento que se repetem, apontá-los e combatê-los caso haja necessidade.

O segundo preceito é o que determina uma ordem entre os participantes de um grupo social, isto é, quem pertencia anteriormente ao grupo tem precedência sobre quem veio após, e, posteriormente, é possível ficar uma questão de ordem para cada integrante que chega ao grupo, priorizando, por sua vez, os mais antigos em detrimento dos mais novos. Para Bert Hellinger (2003, p. 72) "Neste critério, também denominado de hierárquico, o decurso do tempo vinculado a idade de cada integrante assegura a coesão do grupo familiar e proporciona paz ao sistema".

Por sua vez, a terceira lei determina a necessidade de equilíbrio dentro dos relacionamentos estabelecidos em um grupo, desde que se situem em posições equivalentes, apregoando que, para o sucesso de tal relação, é indispensável que haja a preservação da equidade entre os membros. Ainda sobre a questão, Bert Hellinger (2003, p. 77) cita que: 
A preservação da estabilidade relacional se alcança com a constante equiparação entre o crédito e o débito gerado pelo dar e o tomar de forma harmoniosa e equivalente. Neste comando a dinâmica perceptível decorrente da compensação desequilibrada poderá conduzir ao término do relacionamento de casal.

A expressão Direito Sistêmico foi desenvolvida pelo renomado jurista brasileiro Sami Storch, que vem se dedicando ao estudo aprofundado da técnica de Constelação Familiar desde 2004. Tal direito advém de uma análise sob a ótica das ordens que regem as relações entre os homens, sendo baseado na técnica psicoterapêutica das Constelações Familiares que foi estabelecida por Bert Hellinger.

O Direito Sistêmico propõe-se a buscar a solução real de uma relação conflituosa existente entre as pessoas pertencentes a um grupo. O operador do Direito Sistêmico busca compreender o interesse de todas as partes envolvidas em um processo litigioso. Muitas vezes, o conflito tem sua origem em uma frustração passada vivida por uma das partes envolvidas. Sami Storch (2010, p. 01) esclarece que

Uma pessoa atormentada por motivos de origem familiar pode desenvolver uma psicose, tornar-se violenta e agredir outras pessoas. Quem tem a ver com isso? Todos. Toda a sociedade. Adianta simplesmente encarcerar esse indivíduo problemático, ou mesmo matálo (como defendem alguns)? Não. Se ele tiver filhos que, com as mesmas raízes familiares, apresentem os mesmos transtornos, 0 problema social persistirá. A solução sistêmica, nesse caso, deve ter em vista a origem familiar do indivíduo. Não haverá real solução de outra forma.

O Direito Sistêmico que possui como base a Constelação familiar procura humanizar o judiciário, afim de se realizar a pacificação social, a visão do juiz que atuará no litígio deve ultrapassar o que lhe foi apresentado, de tal forma que o operador do direito deva buscar compreender quais são as dificuldades e os reais ensejos daqueles envolvidos no processo. 


\section{O DIREITO SISTÊMICO E O SISTEMA DE CONSTELAÇÃO FAMILIAR DE BERT HELLINGER}

É evidente o crescimento da utilização do Direito Sistêmico nas relações sociais, sendo uma importante ferramenta utilizada na solução de conflitos judiciais.

Tal reconhecimento deixa claro a eficiência do Direito Sistêmico quando aplicado em comunhão com o Sistema de Constelação Familiar. O Direito Sistêmico preocupase com as ordens superiores que regem as relações humanas, utilizando como base as Constelações Familiares criadas por Bert Hellinger.

Criada pelo alemão Bert Hellinger, a Constelação Familiar ao ser aplicada em conjunto com o ordenamento jurídico, traz resultados positivos uma vez que a parte envolvida em um litígio, ao participar do sistema citado, passa por uma análise profunda de todas suas relações interpessoais. Para o escritor Stephan Hausner (2007, p. 123): "Constelação é o coletivo de estrelas de um sistema, por isso a palavra originou o termo constelação familiar, onde o sujeito é o centro do sistema social em que se insere e vivencia naquele momento específico da constelação".

Pode-se considerar a Constelação Familiar como um modelo psicoterápico que possui como estudo as emoções e energias que todos acumulamos. Essa análise gera a compreensão de todos os fatores presentes em um conflito e, se aplicada de forma sistêmica ao Direito, pode auxiliar o juízo a conseguir estabelecer uma resolução consensual de determinado litígio.

Muitas vezes, para que haja a completa análise do sujeito participante de uma Constelação, se faz necessário mais de uma reunião, esta poderá ser conduzida de inúmeras maneiras, no entanto, sempre será conduzida a fim de se analisar a questão central do conflito. Através dessa análise, muitas vezes é possível perceber que o problema que a pessoa expõe, em sua origem, não pertence a ela, e sim ao seu sistema familiar. Fatos como abusos sofridos na infância, mortes precoces, violência doméstica, possuem enorme importância na dinâmica de uma família, podendo influenciar, inclusive, na vida de futuras pessoas de um núcleo familiar. Caberá ao operador do Direito, munido de todas as informações referentes ao sujeito, auxiliá-lo no 
processo de conciliação. A resolução de conflito de acordo com o Sistema de Constelação Familiar origina-se mediante as ordens do amor.

Bert Hellinger estuda o amor de uma forma geral, não aquele restrito ao amor entre casais, e sim aquele que está presente em toda humanidade, e, por conseguinte, em cada indivíduo. Para o psicoterapeuta, as ordens do amor (ou leis do amor) são basicamente três: a Ordem do pertencimento, a Ordem de hierarquia e a Ordem de equilíbrio. Segundo Hellinger (2007, p. 97)

A primeira ordem, de pertencimento, diz respeito ao fato de que, não importa o que uma pessoa faça, ela continuará com o mesmo direito de pertencer à família, à sociedade, ao mundo, independente de estar livre ou recluso ou de estar presente fisicamente na família atual ou não.

Ainda sobre o tema, o referido autor (2007, p. 99) afirma que a segunda Ordem "Diz respeito a quem chegou primeiro no ordenamento familiar, ou seja, sempre os mais velhos merecem ser olhados com muito respeito e cuidado, pois é por meio deles que a família está assim instalada e existe efetivamente".

Bert Hellinger (2007, p. 103) ainda traz expresso em sua obra a definição da terceira Ordem do amor como sendo:

A lei do equilíbrio sempre existe nas ações de dar e receber e segue o raciocínio de que dentro de uma relação interpessoal, ambas as partes devem dar e receber para que haja um equilíbrio e seja encontrada a paz entre as pessoas pertencentes a um núcleo familiar.

Ao se incorporar ao Direito Sistêmico essas três leis criadas por Bert Hellinger, a humanidade só tenderá a encontrar um maior equilíbrio trazendo como consequência positiva a almejada paz social mediante a solução da maioria dos conflitos, que surgem em sua forma primária das relações familiares.

A Constelação Familiar se executa da seguinte forma: primeiramente o operador ou facilitador (aquele que conduz a constelação familiar) coleta informações básicas do agente que está passando pelo sistema. Dando sequência, ele irá orientá-lo a escolher aleatoriamente os representantes, podendo estes ser desenhos, bonecos, objetos ou 
até mesmo pessoas, afim de que possam representar os envolvidos na questão principal do litígio.

A escritora Maria Scarlet do Carmo (2015, p. 15) detalha a aplicação do método da constelação familiar da seguinte forma:

A aplicação do trabalho consiste em que, nós, como clientes numa Constelação, sejamos solicitados pelo facilitador o mínimo possível a respeito de informações a nosso respeito e a respeito do tema que queremos trabalhar. $O$ facilitador pede apenas que digamos o que queremos. Em seguida somos convidados pelo facilitador a escolher, aleatoriamente, entre pessoas de um grupo, ou figuras quando do trabalho individual, ou desenhos, algo ou alguém que possa representar a questão por nós colocada e posicioná-los no espaço seguindo nossos sentimentos ou percepção interna.

O Direito Sistêmico se propõe a uma verdadeira solução para um conflito existente entre as partes e a atender a todos os interesses das partes envolvidas no conflito. Segundo Storch (2010, p. 05),

O direito sistêmico se propõe a encontrar a verdadeira solução. Essa solução não poderá ser nunca para apenas uma das partes. Ela sempre precisará abranger todo o sistema envolvido no conflito, porque na esfera judicial - e às vezes também fora dela - basta uma pessoa querer para que duas ou mais tenham que brigar. Se uma das partes não está bem, todos os que com ela se relacionam poderão sofrer as consequências disso.

O Direito Sistêmico quando utiliza como base a Constelação Familiar visa humanizar o judiciário, já que, no momento em que busca a pacificação social, o Juiz deve observar a situação, levando em consideração, além dos seus conhecimentos jurídicos, as informações coletadas durante o desenvolvimento do processo de Constelações Familiares, com a intenção de entender a essência do problema apresentado, relacionando-o com as dificuldades presentes de cada um dos envolvidos na ação.

Para Storch (2010, p. 07), a utilização do Direito Sistêmico através dos sistemas de Constelações Familiares é importante pois, 
Mesmo tendo as leis positivadas como referência, as pessoas nem sempre se guiam por elas em suas relações e os autos de um processo judicial dificilmente refletem essa realidade complexa. Assim, por meio deste método, vêm à tona dinâmicas que estavam ocultas naquela família, conflitos e traumas que envolveram antepassados e que projetaram seus afeitos ao longo das gerações seguintes, causando os efeitos atualmente sentidos pelo cliente.

Ao entender que a origem de muitos problemas está diretamente ligada a situações pessoais de cada envolvido, e, ao realizar a Constelação do sujeito, o juiz poderá ampliar sua visão, podendo assim encontrar uma solução que se positiva para ambas as partes.

A técnica que tem sua utilização reconhecida pelo artigo 3ํ do CPC está tendo alta aplicabilidade na resolução de conflitos em ações pertencentes ao Direito de família. A resolução do conflito deve envolver todas as partes, isto é, todo o sistema família. Por exemplo, em uma ação de divórcio, a decisão proferida pelo juiz de nada adiantará se os pais continuarem se atacando, e a situação afetará os filhos, já que são sistematicamente ligados aos pais. Ao buscar a resolução sistêmica, há de se considerar a realidade da criança e de ambos os pais, para que assim se consiga a almejada conciliação entre as partes.

Segundo artigo produzido pelo CNJ em 2015, a aplicação da Constelação Familiar trouxe resultados expressivos e positivos:

Com ajuda da chamada Constelação Familiar, [...], o magistrado Sami Storch conseguiu índice de acordo de $100 \%$ em processos judiciais onde as partes participaram do método terapêutico. Já no Tribunal de Justiça de Mato Grosso do Sul, a Constelação Familiar passou a ser implantada por meio da formalização de um convênio entre a Coordenadoria da Infância e Juventude (CIJ) com um grupo de terapeutas sistêmicos (CONSELHO NACIONAL DE JUSTIÇA, 2015, p. 01).

O atual Código de Processo Civil (BRASIL, 2015a) trouxe inúmeras mudanças ao ordenamento jurídico, dentre elas, a elencada no artigo 694, que dá referida importância aos métodos de autocomposição executados com a ajuda de profissionais de outras áreas, ao explicitar que 
Nas ações de família, todos os esforços serão empreendidos para a solução consensual da controvérsia, devendo o juiz dispor do auxílio de profissionais de outras áreas de conhecimento para a mediação e conciliação. Parágrafo único. A requerimento das partes, o juiz pode determinar a suspensão do processo enquanto os litigantes se submetem a mediação extrajudicial ou a atendimento multidisciplinar.

Em conformidade com o referido dispositivo, está a aplicação do método de Constelação Familiar, que tem como objetivo ampliar a consciência das partes envolvidas em um litígio. Esse método baseia-se na análise racional e dinâmica apresentada, em que, muitas vezes, acaba por revelar situações ocultas de cada participante do Sistema. Segundo o CNJ, em sua publicação no ano de 2015:

No ano de 2012, o Juiz Sami Storch, da $2^{\text {a }}$ Vara de Família de Itabuna (BA), aplicou a técnica de Constelação Familiar a alguns casos, sendo um dos primeiros magistrados a adotá-la, esta experiência demonstrou que quando uma das partes envolvidas no litígio, era submetida a esta técnica psicoterapêutica o índice de acordos chegou a 91\%, já quando ambas as partes eram submetidas, houve 100\% de conciliação (CONSELHO NACIONAL DE JUSTIÇA, 2015, p. 03).

$\mathrm{Na}$ atualidade, o referido método vem tendo sua aplicabilidade no poder judiciário de forma anterior à audiência de conciliação e mediação, por ser um Sistema que se adapta conforme o caso, para cada qual é desenvolvido uma tática de abordagem, sempre levando em consideração os preceitos e as leis sustentadas pela Constelação Familiar. O método busca a resolução consensual de litígio trazendo consigo a harmonização das relações familiares.

As constelações são utilizadas como valioso instrumento de apoio aos que operam o direito, são estas responsáveis em revelar as posturas que serão adequadas durante o julgamento do litígio. Segundo Storch (2015, p. 22), expõe que

As técnicas aplicadas vêm auxiliando na efetivação de conciliações verdadeiras entre as partes. Durante e após 0 trabalho com constelações, os participantes têm demonstrado boa absorção dos assuntos tratados, um maior respeito e consideração em relação à outra parte envolvida, além da vontade de conciliar - o que se comprova também com os resultados das audiências de conciliação realizadas semanas depois (os índices de acordos superam os 90\%) e com os relatos das partes e dos advogados. 
Ao se optar pela realização do Sistema de Constelação anterior à audiência de mediação e conciliação, muitas vezes durante a análise do envolvido, é possível perceber de antemão a mudança de comportamento. $O$ indivíduo, ao ser posto em confronto com os verdadeiros sentimentos ali presentes, torna-se mais suscetível à realização de um acordo em momento posterior. Sami Storch (2015, p. 22) cita que:

Posteriormente, quando da realização das audiências de conciliação, os acordos acontecem de forma rápida e até emocionante, pois os que participaram das vivências tendem a desarmar seus corações e reconhecer que, por trás das acusações e dos rancores mútuos, existe um sentimento de amor verdadeiro e a dor da frustração.

A resolução do litígio, em sua forma consensual, quando realizado através do Sistema de Constelação Familiar, além aperfeiçoar a utilização da Justiça, acaba muitas vezes, auxiliando no próprio desenvolvimento familiar, tornado o ambiente mais saudável a todos os envolvidos e, segundo Sami Storch (2015, p. 25),

Dessa forma, além de contribuir para o aperfeiçoamento da Justiça, a prática também auxilia a melhorar a qualidade dos relacionamentos nas famílias - que, sabendo lidar melhor com os conflitos, podem viver mais em paz e assim proporcionar um ambiente familiar melhor para 0 crescimento e desenvolvimento dos filhos, com respeito e consideração à importância de cada um. Consequência natural disso é a melhora nos relacionamentos em geral e a redução dos conflitos na comunidade.

Para o Jurista Sami Storch, os autos de um processo dificilmente irão apontar a causa do litígio de forma profunda, tampouco sua origem e, por isso, propõe que o conhecimento das constelações familiares pode oportunizar uma melhor compreensão do conflito, podendo, assim, levar a uma resolução mais eficaz e satisfatória. Storch (2015, p. 23) defende que

O uso desse método faz emergir novas possibilidades de entender o contexto dos conflitos e trazer soluções que causam alívio a todos os envolvidos". O mero conhecimento dessas ordens ocultas, descritas por Hellinger como as "ordens do amor", permite a compreensão das dinâmicas dos conflitos e da violência de forma mais ampla, além das aparências, facilitando ao julgador adotar, em cada caso, o posicionamento mais adequado à pacificação das relações envolvidas. 
Storch, considerado o precursor na aplicabilidade e desenvolvimento do Direito Sistêmico no Brasil, cita que a visão sistêmica vem auxiliando-o em sua prática jurídica desde que ingressou na magistratura, prestando todo o suporte necessário na compreensão dos casos interpessoais. Além disso, Storch realiza palestras e cursos através dos quais repassa seu conhecimento acerca do tema. Storch (2015, p. 21) explica que:

Uma das bases do direito sistêmico é a consideração pela pessoa e pela bagagem que ela traz (família). Um indivíduo não pode ser tratado isolado, ele tem que ser encarado como um sistema, formado por ele próprio, pelo pai e pela mãe. Se quisermos conhecer alguém ou a nós mesmos nós precisamos assimilar a origem desse ser. Todos gostam de ser reconhecidos. Muitas pessoas ingressam com processos na Justiça por conta de um motivo, mas quando é feita a análise mais profunda, é possível verificar que o problema maior é que elas foram desconsideradas pelo outro ou sofreram um gesto de não reconhecimento.

Sendo importante ressaltar ainda que, as Constelações devem ser realizadas por um agente que tenha treinamento na área. $O$ facilitador não necessariamente necessita possuir o conhecimento do Direito, nesses casos o juiz poderá acompanhar a sessão. Segundo a pesquisadora Anna Carolina Masiero (2016, p. 33):

Cumpre ressaltar, ainda, que as Constelações podem ser realizadas por pessoas que tenham treinamento na área. $O$ facilitador não precisa necessariamente ter conhecimento em Direito, e pode agir em conjunto com o profissional jurídico. O Direito Sistêmico ainda não pode ser considerado uma ciência, tendo em vista que está em fase de definição. A psicoterapia Constelações Sistêmicas, nesta proposta, está sendo introduzida como uma ferramenta para o Direito, que pode ser aplicada em qualquer momento da lide, antes ou durante o processo.

Na sentença proferida, não há a expressa necessidade de constar que fora realizada uma Constelação Sistêmica. Esse método servirá para a orientação das partes e do juízo que buscará a melhor decisão a ser tomada. Em nenhuma hipótese, os litigantes são obrigados a participar de uma Constelação, sendo da vontade da parte participar, e o procedimento pode ser realizado ainda que apenas uma das partes assim deseje. 
Sami Storch aponta que existem diversas áreas e casos em que é possível a aplicação das Constelações Familiares, tais como: interrogatório de crianças e adolescentes, na área criminal relacionado à agressores; constelações com adolescentes autores de atos infracionais, etc.

A utilização do Direito Sistêmico associado à técnica das Constelações Familiares traz inúmeros benefícios ao Ordenamento Jurídico Brasileiro. A resolução consensual de litígios é amplamente difundida e incentivada por todos os órgãos e operadores do Direito e tais práticas são consideradas positivas, uma vez que propiciam aos envolvidos o meio mais humanizado, justo e menos prejudicial de se obter um direito durante um litígio.

\section{CONSIDERAÇÕES FINAIS}

No Direito Sistêmico, o uso da técnica de Constelação Familiar vem modificando o Sistema Judiciário Brasileiro. Neste processo ocorre a proximidade entre os familiares e acordantes. Antes das audiências são realizadas as Constelações Familiares que são medidas estabelecidas e organizadas de modo a viabilizar que os diferentes ocupantes de cada posição nas relações envolvidas possam ser ocupadas e se expor no experimento dos sentimentos e afeições envolvidos pelo outro, sendo uma espécie de racionalização da empatia envolvida em uma determinada questão.

Quando acordantes ou familiares desocupam suas posições nas relações em que, normalmente, estão defendendo interesses próprios, sentindo e experimentando a posição do outro, automaticamente, reduzem o fator crítico da parte envolvida, experimentando uma espécie de compreensão que está umbilicalmente atrelada ao sucesso e êxito. $O$ alto índice na solução de conflitos em alguns Estados do Brasil chama a atenção para trabalhos científicos como este em que juízes e outros membros do judiciário ou não realizam encontros entre os envolvidos acordantes e promovem uma maior celeridade e resolução de conflitos familiares.

O Direito Sistêmico abarca as Constelações Familiares que acabam sendo consagradas e reconhecidas pelos benefícios trazidos na solução de litígios. A resolução consensual é amplamente difundida e incentivada por todos os órgãos e 
operadores do Direito, pois tais práticas são consideradas positivas uma vez que propiciam aos envolvidos o meio mais humanizado, justo e menos prejudicial de se obter um direito durante um litígio.

Alguns casos desenvolvidos e relatados por juízes de diferentes Estados no Brasil deixam claro que a aplicação da técnica de Constelação Familiar, que tem como objetivo ampliar a consciência das partes envolvidas em um litígio, é muito eficaz e provoca a revelação de situações ocultas de cada participante do Sistema e promove uma conciliação verdadeira em atos litigiosos.

Por isso, o êxito verificável no ano de 2012, em que o Juiz Sami Storch, da $2^{\mathrm{a}}$ Vara de Família de Itabuna, no Estado da Bahia, aplicou a técnica de Constelação Familiar em casos de litígios, sendo um dos primeiros magistrados a adotá-la, e o resultado chamou a atenção quando demonstrou o expressivo índice de $91 \%$ de acordos quando apenas uma das partes participava da constelação e, nas hipóteses em que ambas as partes eram submetidas às constelações familiares, um percentual de $100 \%$ de conciliação.

\section{REFERÊNCIAS}

BACELLAR, Roberto Portugal. Juizados Especiais: a nova mediação paraprocessual. São Paulo: RT, 2003

BRASIL. Conselho Nacional de Justiça. Resolução no 125, de 29 de novembro de 2010. Disponível em: <http://www.cnj.jus.br/busca-atos-adm?documento=2579>. Acesso em: 12 abr. 2018.

. Lei no 13.105, de 16 de março de 2015a. Disponível em:

<http://www.planalto.gov.br/ccivil_03/_ato2015-2018/2015/lei/l13105.htm>. Acesso em: 12 abr. 2018.

. Lei no 13.140, de 26 de junho de 2015b. Disponível em: <http://www.planalto.gov.br/ccivil_03/_ato2015-2018/2015/lei/l13140.htm>. Acesso em: 12 abr. 2018.

. Lei no 9.307, de 23 de setembro de 1996. Disponível em:

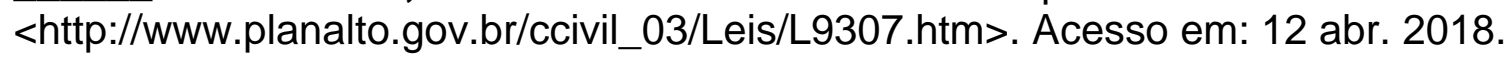


CARMO, Maria Scarlet do. Uma breve apresentação sobre a Constelação Sistêmica Fenomenológica. São Paulo: Editora Atlas, 2015.

FREGAPANI, Guilherme Silva Barbosa. Formas alternativas de solução de conflitos e a lei dos juizados especiais cíveis. Revista da informação legislativa. Brasília, a, v. 34, 1997. Disponível em: <https://www2.senado.leg.br/bdsf/bitstream/handle/id/199/r133 11.PDF?sequence=4>. Acesso em: 07 jun. 2017.

HAUSNER, Stephan Constelações familiares e o caminho da cura: a abordagem da doença sob a perspectiva de uma medicina integral / Stephan Hausner ; tradução Newton A. Queiroz. - São Paulo: Cultrix, 2010.

HELLINGER, Bert. Constelações Sistêmicas e Familiares. São Paulo: Cultrix, 1999.

. As ordens do amor: um guia para o trabalho de constelações familiares. São Paulo: Cultrix, 2007.

LEITE, Carlos Henrique Bezerra. Curso de direito processual do trabalho. 5. ed. São Paulo: LTr, 2007.

MASIERO, Ana Carolina. Aplicabilidade da Constelação Sistêmica no âmbito do Direito. Minas Gerais: UFMG, 2016.

NAZARETH, Eliana Riberti. Mediação: algumas considerações. Revista do Advogado , v. 26, p. 129-133, 2006.

SERPA, Maria de Nazareth. Mediação, processo judicioso de resolução de conflitos. Minas Gerais: UFMG, 1997.

STORCH, Sami. Direito Sistêmico: primeiras experiências com constelações no judiciário. Revista Filosofia, Pensamento e Prática das Constelações Sistêmicas. $n$. 04. São Paulo: Conexão Sistêmica, 2015.

. O que é direito sistêmico. 2010. Disponível em:

$<$ https://direitosistemico.wordpress.com/2010/11/29/o-que-e-direito-sistemico >. Acesso em: 12 abr. 2018. 